\title{
ANTIBACTERIAL ACTIVITY OF MODERATELY VOLATILE COMPONENTS OF THE OIL EXTRACTED FROM THE SEEDS OF DACRYODES EDULIS G. LAM
}

\section{RAPHAEL C MORDI ${ }^{1}$, GRACE I OLASEHINDE ${ }^{2 *}$, ADEBOLA P OKEDERE ${ }^{1}$, ARNOLD N ELEGWULE ${ }^{1}$, JOAN I AYO-AJAYI ${ }^{1}$, HASSANA O JOHNATHAN ${ }^{1}$, ADEOLA E ONIBOKUN ${ }^{2}$, ADESOLA A AJAYI ${ }^{3}$, DANIEL $O$ UCHENNA ${ }^{2}$}

${ }^{1}$ Department of Chemistry, College of Science and Technology, Covenant University, Canaanland, Ota, Ogun state, Nigeria, ${ }^{2}$ Department of Biological Sciences, College of Science and Technology, Covenant University, Canaanland, Ota, Ogun state, Nigeria, ${ }^{3}$ Department of Biological Sciences, Augustine University, Epe, Lagos State, Nigeria. Email: grace.olasehinde@covenantuniversity.edu.ng

Received: 08 October 2018, Revised and Accepted: 21 November 2019

\section{ABSTRACT}

Objectives: Dacryodes edulis is a versatile plant in many African countries, as its various parts are employed to treat several diseases. Like most plants used in traditional medicine, the possible mechanism by which $D$. edulis functions is still unknown. This study was designed to investigate the components of the plant seed with a view of justifying its use as traditional medicine.

Methods: The seed oil of D. edulis was exhaustively extracted with a Soxhlet extractor from $500 \mathrm{~g}$ seeds and $200 \mathrm{~g}$ seeds of D. edulis using ethanol and petroleum ether as solvent, respectively. The extraction solvent was removed to obtain the oil which was then subjected to antimicrobial activity test to determine its activity against the following clinical isolates namely Pseudomonas aeruginosa, Staphylococcus aureus, Bacillus cereus, and Escherichia coli using gentamycin as positive control. Phytochemical screening and gas chromatography-mass spectrometry (GC-MS) analyses were carried out following standard methods

Results: Ethanolic extract resulted in a higher percentage of oil yield (11.6\%) than petroleum ether (5.3\%). D. edulis seed oil showed remarkable activity against Gram-negative and Gram-positive isolates: E. coli, Bacillus spp, and S. aureus but not against P. aeruginosa. The presence of saponins, quinones, cardiac glycosides, terpenoids, and phenol was confirmed during qualitative phytochemical screening, and the preliminary results from GC-MS analysis show the presence of terpinen-4-ol, 4,6,6-trimethyl bicyclo[3.1.1]hept-3-en-2-one, ethyl 14-methyl-hexadecanoate, methyl 19-methyleicosanoate, squalene, C-14 to C-18 fatty acids, and their esters.

Conclusion: The study, therefore, confirms that the use of $D$. edulis as component of traditional medicine may be justified.

Keywords: Seeds, Oil, Phytochemicals, Dacryodes edulis, Antimicrobial activity.

(c) 2019 The Authors. Published by Innovare Academic Sciences Pvt Ltd. This is an open access article under the CC BY license (http://creativecommons. org/licenses/by/4. 0/) DOI: http://dx.doi.org/10.22159/ajpcr.2019.v12i3.30161

\section{INTRODUCTION}

About $80 \%$ of the entire world population rely on alternative/ traditional medicine to provide their basic health-care needs [1]. Numerous secondary metabolites with biological activity are currently being exploited in the developing countries in medicine and alternative medicine because of lack of or inadequate health-care facilities for the treatment of ailments. The probable mechanisms by which these secondary metabolites function is not known [2]. Because of the widespread use of plants, there is the need to explore and identify the components of the concoctions used in treatments. The wide-spread use of plant-based medicinal drugs is due to their low cost and ready availability [3]. One such plant that has been used in the treatment is D. edulis, commonly known as African pear. The plant is widely cultivated in many African countries such, including Sierra Leone, Uganda, Angola, Zimbabwe, and Nigeria [4]. The pulp of which is known to possess an extensive range of medicinal, pharmacological, and biological properties that are highly beneficial to human health. It is known to have antimicrobial, antihypertensive, diuretic, and antispasmodic properties $[5,6]$. The fruit is seasonal and is extensively used in aromatherapy, traditional, or alternative medicine to treat several ailments [4]. Extracts from the plant have been used in treating skin diseases, dysentery, and fever [7]. The antimicrobial and antioxidant activities of its components were confirmed [4]. Its use in the treatment of snakebite in Southwest Cameroon is also reported [8]. The fruit is an excellent source of minerals and Vitamins E and C, and it is also known to be rich in thiamine, magnesium, niacin, potassium, calcium, carbohydrate, riboflavin, amino acids, phosphorus, fiber, and Vitamin B6 [6]. The oxidative stability of the African pear oil has been proven to have potentials of preventing skin irritation which makes it useful in cosmetics [5]. By identifying and characterizing the components of the plant, we can begin to understand their mechanism of action.

\section{METHODS}

\section{Sample preparation}

The seed of $D$. edulis was authenticated by a botanist and assigned a code/accession and voucher number. The pulp was removed from the pulp and shell using a knife and was allowed to dry in open air at room temperature for 1 week after which it was ground using mortar and pestle. The seed was kept in an airtight water-resistant bag till the time of extraction.

\section{Extraction}

Five hundred grams of the dried ground $D$. edulis seed were measured and placed in the thimble in a Soxhlet extractor with ethanol as the solvent for exhaustive extraction. After extraction, the solvent was removed using the rotary evaporator. The same procedure was applied for another batch of extraction using petroleum ether $\left(60-80^{\circ} \mathrm{C}\right)$ as solvent.

Phytochemical screening

Qualitative phytochemical tests were carried out on the D. edulis seed extract to determine the different constituents present in the extract [9]. 
Antimicrobial test

The $D$. edulis seed extract was subjected to antimicrobial activity test using agar well diffusion assay as described by Olasehinde et al.[10]. The test organisms were Bacillus cereus, Escherichia coli, Pseudomonas aeruginosa, and Staphylococcus aureus.

The positive and negative controls were set up. Antimicrobial activity of the seed oil was determined by taking measurement of the diameter of the zone of inhibition in millimeter, and the minimum inhibitory concentration for each of the test organism was determined by adopting broth dilution methods. The lowest concentration of the extract which inhibited the growth of the inocula was considered as the minimum inhibitory concentration.

\section{Partitioning}

Twenty-five milliliters of concentrated ethanolic crude extract of $D$. edulis seed oil were partitioned between petroleum ether and distilled water, and the water layer was further partitioned between dichloromethane and distilled water. All the partitioning was carried out in solvent ratio of 1:1 in a separating funnel. The organic layers were concentrated using the rotary evaporator, and the concentrated extract was analyzed using gas chromatography-mass spectrometry (GC-MS).

\section{Gas chromatographic-mass spectrometry}

The GC-MS analysis was carried out at the Shimadzu Training Center for analytical instruments (STC) Lagos. The GCMS instrument used for the analysis was GCMS-QP2010SE, Shimadzu, Japan. The machine comprises of injector and GC interfaced to the mass spectrophotometer. The GC condition was as follows: Column oven temperature $\left(60^{\circ} \mathrm{C}\right)$, injection temperature $\left(200^{\circ} \mathrm{C}\right)$, injection mode split ratio $(1: 1)$, helium as carrier gas flow rate $(1.56 \mathrm{ml} / \mathrm{min})$, the system was temperature program from $60^{\circ} \mathrm{C}$ (at $10^{\circ} \mathrm{C} / \mathrm{min}$ ) to $160^{\circ} \mathrm{C}$ (held for $2 \mathrm{~min}$ ) then at $\left(10^{\circ} \mathrm{C} / \mathrm{min}\right.$ ) to $250^{\circ} \mathrm{C}$ and the injection volume was $0.5 \mu \mathrm{L}$. Mass spectrophotometer condition: Ion source temperature $200^{\circ} \mathrm{C}$ and Interface temperature $250^{\circ} \mathrm{C}$ solvent cut time $4.5 \mathrm{~min}$ and acquisition was in the scan mode.

\section{RESULTS AND DISCUSSION}

The code number of the seed is OgCUNo813 and accession number is De/Bio/H813. The extraction with ethanol yielded $58.2 \mathrm{~g}(11.60 \%)$ and petroleum ether yielded $10.6 \mathrm{~g}$ (5.3\%) (Table 1). These quantities of the oil obtained from the extraction are much smaller than the $59 \%$ of yield in a previous report [11] where hexane was used as the extracting solvent.

\section{Antimicrobial sensitivity test}

The results of the antimicrobial test and the determination of the minimum inhibitory concentration on the ethanol extract of $D$. edulis are presented in Tables 2 and 3. It was observed that the ethanolic extract of D. edulis showed good, noticeable, and remarkable activity against the test organisms as compared with the standard drug, Gentamycin. The MIC recorded against $S$. aureus was $31.25 \mathrm{mg} / \mathrm{mL}$, whereas that of $E$. coli and $B$. cereus was $125 \mathrm{mg} / \mathrm{mL}$. $P$. aeruginosa showed no sensitivity to the seed oil extract and the control (Gentamicin) as there was no zone of inhibition recorded for all the concentrations used. The seed oil showed appreciable antibacterial activities against the test organisms. This corroborates the earlier findings on antimicrobial efficacy of the crude extracts of $D$. edulis $[4,7,8]$. However, the MIC values obtained as higher than an earlier report by [12] where ethyl acetate, chloroform, hexane, and methanol extract were tested against similar clinical isolates. The antibacterial activities of these plants may be due to the saponins, quinones, cardiac glycosides, terpenoids, and phenol identified in the plants. Previous research has reported these phytochemicals [13-15].

\section{Phytochemical screening}

Table 4 shows the detailed results of the qualitative analysis of the phytochemical components of the ethanolic extract of $D$. edulis seed oil. The extract contained saponins, quinones, cardiac glycosides, terpenoids, and phenol. However, some of the phytochemicals present in the fruit oil such as flavonoids, alkaloids, and tannins as reported by $[4,16,17]$ were either absent or not detected in the seed oil extracted.

\section{Gas chromatography-mass spectrometry analysis}

Fig. 1 shows the chromatogram of the petroleum ether crude extract obtained from the $D$. edulis seeds. The GCMS analysis of the crude petroleum ether extract showed 57 peaks, and some of the peaks were selected because of their intensity, percentage area, and similarity index of the mass spectrophotometer. The selected and identified peaks have been numbered in the chromatograms and some of these selected

Table 1: Dacryodes edulis seed oil yield

\begin{tabular}{llll}
\hline Solvent for extraction & Mass of seed used (g) & Mass of oil obtained (g) & Percentage of oil obtained (\%) \\
\hline Ethanol & 500 & 58.2 & 11.6 \\
Petroleum ether & 200 & 10.6 & 5.3 \\
\hline
\end{tabular}

Table 2: Antimicrobial activity of seed oil of Dacryodes edulis (zone of inhibition)

\begin{tabular}{|c|c|c|c|c|c|c|c|c|}
\hline \multirow[t]{2}{*}{ Test organism } & \multicolumn{7}{|c|}{ Diameter of zones of inhibition (mm) at different concentrations (mg/mL) } & \multirow{2}{*}{$\begin{array}{l}\text { Gentamicin (control) } \\
250\end{array}$} \\
\hline & 1000 & 500 & 250 & 125 & 62.5 & 31.25 & 15.63 & \\
\hline Staphylococcus aureus & 35 & 30 & 30 & 30 & 25 & 23 & - & 35 \\
\hline Pseudomonas aeruginosa & - & - & - & - & - & - & - & - \\
\hline Bacillus cereus & 15 & 12 & 12 & 10 & - & - & - & 25 \\
\hline Escherichia coli & 25 & 20 & 15 & 15 & - & - & - & 30 \\
\hline
\end{tabular}

Table 3: Minimum inhibitory concentration of seed oil of Dacryodes edulis

\begin{tabular}{llll}
\hline Test organism & Staphylococcus aureus & Pseudomonas aeruginosa & Bacillus cereus \\
\hline MIC $\mathrm{mg} / \mathrm{ml}$ & 31.25 & $>1000$ & 125.0 \\
\hline
\end{tabular}

MIC: Minimum inhibitory concentration

Table 4: Phytochemical screening for the ethanolic extract of Dacryodes edulis

\begin{tabular}{lllllll}
\hline Classes of compounds & Saponin & Quinones & Cardiac glycosides & Terpenoids & Phenol & Coumarins \\
\hline Remarks & ++ & ++ & ++ & ++ & ++ & ++ \\
\hline
\end{tabular}




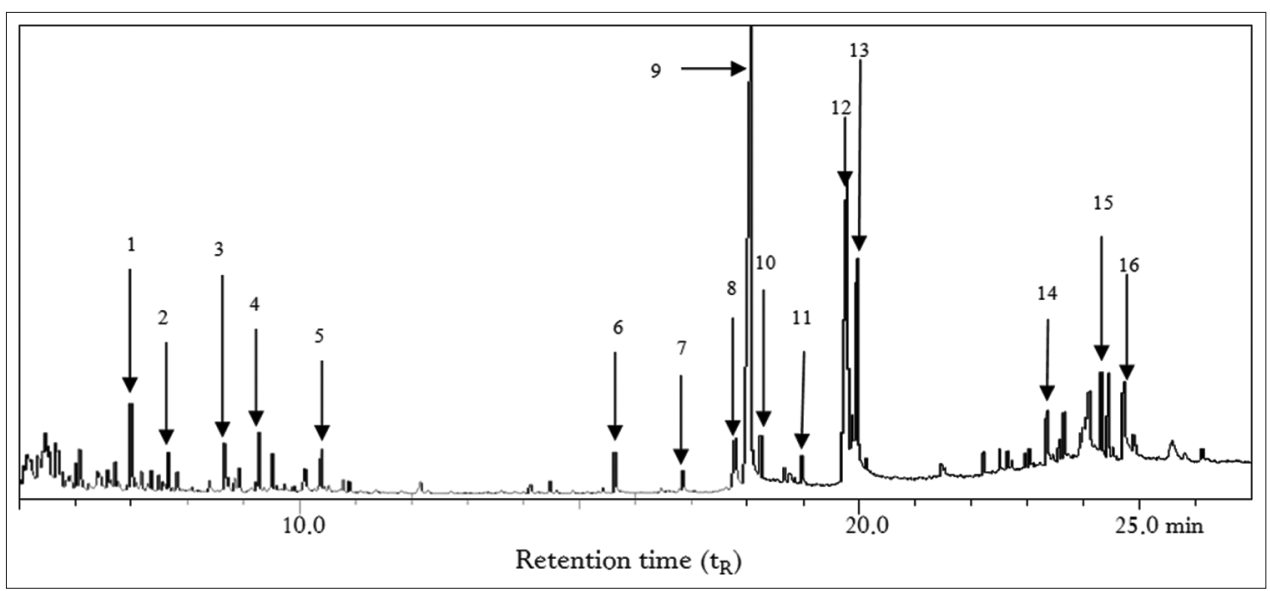

Fig. 1: Gas chromatography-mass spectrometry chromatogram of the petroleum ether crude extract of Dacryodes edulis seed. 1 - cisp-mentha-1-(7),8-dien-2-ol (6.982 min); 2 - 2-methyl-5-(1methylethenyl)-2-cyclohexen-1-ol (7.650 min); 3 - 4- (1-methylethenyl)-2cyclohexene-1-one (8.662 min); 4 - 4,6,6-Trimethyl bicyclo[3,1,1]-hept-3-en-2-one (9.274 min); 5-7,7-Dimethyl-3-methylenebicyclo[4.1.0] hepten-2-ol (10.384 min); 6 - Tetradecanoic acid (15.629 min); 7 - Pentadecanoic acid (16.842 min); 8 - Z-11-Hexandecenoic acid (17.774 min); 9- n-Hexadecanoic acid (18.056 min); 10 - ethyl hexadecanoate (18.229 min); 11 - Eicosanoic acid (18.973 min); 12 - E-9Octadecenoic acid (19.767 min); 13 - Octadecanoic acid (19.957 min); 14 - 2-Hydroxy-1-(hydroxymethyl) ethyl hexadecanoic acid ester (23.342 min);15 - Squalene (24.315 min); 16 - Propylene glycol monoleate (24.713 min)

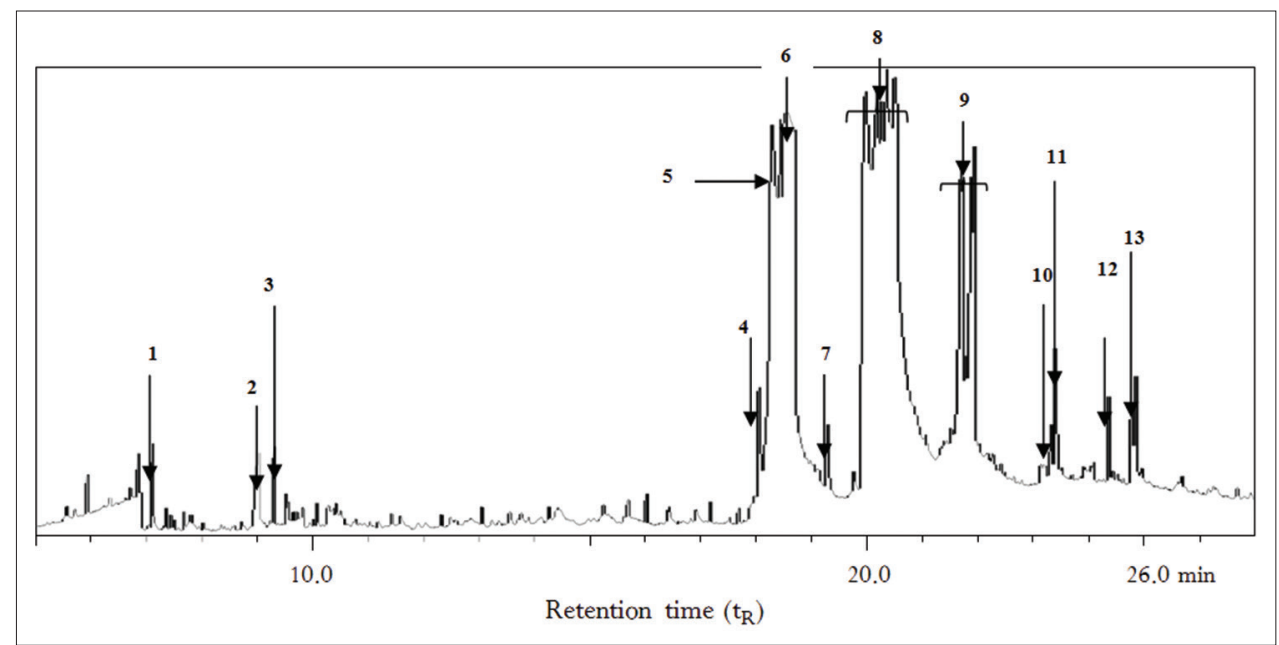

Fig. 2: Gas chromatography-mass spectrometry chromatogram of crude ethanol extract of Dacryodes edulis seed. 1 - Terpinen4-ol (7.102 min); 2 - 5-hydroxymethylfurfural (9.006 min); 3 - 4,6,6-trimethyl Bicyclo[3.1.1]hept-3-en-2-one (9.299 min); 4 - Ethyl -9-hexadecenoate; 5 - Ethyl Hexadecanoate (18.284 min); 6 - $n$-hexadecanoic acid (18.527 min); 7 - 1-(+) 2,6-dihexadecanoateAscorbic acid (19.280 min); 8 - these are C18 fatty acids and their esters; 9 - these are eicosanoic acids and their esters(21.929 min); 10 - Docosanoic acid (23.317); 11 - Ethyl docosanoate(23.394 min); 12 - 2,6,10,14,18-Pentamethyl-2,6,10,14,18eicopentene or squalene (24.360 min); 13 - Ethyl 14-methylhexadecanoate(24.851 min)

compounds were identified by comparison of their mass spectra with literature spectra. The GC-MS analysis conducted on the crude ethanol extract shows about 59 peaks, again as with the chromatogram of the petroleum ether extract; some of the peaks were selected and numbered as shown in the chromatogram (Fig. 2). The numbers in parenthesis are the retention times of the identified compounds. Some of these compounds were reported by Okwu et al.[18] while working on the stem bark of this plant. They also reported some nitrogen compound, which we did not detect in the seed oil. These compounds have found application in medicine, as anti-inflammatory, insectifuge, nematicides anti-acne, as antiarthritic agents [19].

\section{CONCLUSION}

The oil extracted with petroleum or ethanol as solvent from D. edulis has been analyzed by GCMS and shown to be composed mainly of fatty acids and their esters and some terpenoids. The oil was found to have antimicrobial properties, which leads us to believe that the use of parts of the plant in traditional medicine may be justified.

\section{ACKNOWLEDGMENT}

The authors hereby acknowledge the Covenant University Centre for Research, Innovation and Discovery (CUCRID).

\section{CONFLICT OF INTEREST}

The authors have declared that there is no conflict of interest.

\section{AUTHOR CONTRIBUTION}

R.C. Mordi: Experimental design and oversight of GC-MS Procedure, G. I. Olasehinde: Experimental design and antimicrobial assessment, A. P. Okedere, J. I. Ayo-ajayi, H. O. Johnathan: Performed the laboratory procedures for GC-MS analyses in Chemistry laboratory, A. N. Elegwule: 
Involved in sample collection, A. E. Onibokun: Writing and editing of manuscript, A. A. Ajayi: Editing of manuscript and D. O. Uchenna: Involved in laboratory procedures

\section{REFERENCES}

1. Eltayeb IM, Hamid AS. Phytochemical screening and antimicrobial activity of Thuja occidentalis seeds extracts against the isolated common skin infecting microorganisms. Int J Pharm Pharm Sci 2017;9:131-4.

2. El-Ahmady SH, Ashour ML, Wink M. Chemical composition and antiinflammatory activity of the essential oils of Psidium guajava fruits and leaves. J Essent Res 2013;25:475-81.

3. Abdurrazak M, Rao MU, Ado AB, Mohd KS, Zin T. Some natural products and their secondary metabolites attributed towards diabetic cure: A review. Int J Pharm Pharm Sci 2015;7:22-8.

4. Ajibesin KK. Dacryodes edulis (G. Don) H. J. Lam: A review on its medicinal, phytochemical and economical properties. Res J Med Plants 2011;5:32-41.

5. Ikhuoria EU, Maliki M. Characterization of avocado pear (Persea americana) and African pear (Dacryodes edulis) extracts. Afr J Biotechnol 2007;6:950-2.

6. Bratte L, Mmereole FU, Akpodiete OJ, Omeje SI. The nutritional composition of seeds of African pear (Dacryodes edulis) and its implication for non-ruminant nutrition. Pak J Nutr 2010;9:225-57.

7. Egharevba RK, Ikhatua MI. Ethno-medicinal use of plants in the treatment of various skin diseases in Ovia North East, Edo state, Nigeria. Res J Agric Biol Sci 2008;4:58-64.

8. Jiofack T, Fokunang C, Guedje, N, Kumeuze V, Fongnzossie E, Nkongmeneck BA, et al. Ethnobotanical uses of medicinal plants of two ethnoecological regions of Cameroon. Int J Med Med Sci 2010; 2:60-79.

9. Njoku OV, Obi C. Phytochemical constituents of some selected medicinal plants. Afr J Pure Appl Chem 2009;3:228-33.

10. Olasehinde GI, Akinlabu DK, Owoeye FT, Owolabi EF, Audu OY, Mordi RC. Phytochemical and antimicrobial properties of oil extracts from the seeds of Ricinodendron heudelotii. Res J Med Plants 2016;10:362-5.

11. Ogunsuyi HO. Production of biodiesel using African pear (Dacryodes edulis) seed-oil as feedstock. Acad J Biotechnol 2015;3:85-92.

12. Anyam JN, Tor-Anyiin T, OgbajiIgoli J. Studies on Dacryodes edulis 1: Phytochemical and medicinal principles of raw seeds J Nat Prod Plant Resour 2015;5:13-9.

13. Aires A, Marrinhas E, Carvalho R, Dias C, Saavedra MJ. Phytochemical composition and antibacterial activity of hydroalcoholic extracts of Pterospartum tridentatum and Mentha pulegium against Staphylococcus aureus Isolates. Biomed Res Int 2016;2016:11.

14. Murugan T, Wins JA, Murugan M. Antimicrobial activity and phytochemical constituents of leaf extracts of Cassia auriculata. Indian J Pharm Sci 2013;75:122-5.

15. Bhat RS, Al-Daihan S. Phytochemical constituents and antibacterial activity of some green leafy vegetables. Asian Pac J Trop Biomed 2014;4:189-93.

16. Okwu DE, Nnamdi FU. Evaluation of the chemical composition of Dacryodes edulis and Raphia hookeri mannand wendi exudates used in herbal medicine in South Eastern Nigeria. Afr J Tradit Complement Altern Med 2008;5:192-200.

17. Duru M, Amadi C, Ugbogu A, Eze A, Amadi B. Phytochemical, vitamin and proximate composition of Dacryodes edulis fruit at different stages of maturation. Asian J of Plant Sci Res 2012;2:437-41.

18. Okwu DE, Ighodaro BU. GC-MS Evaluation of the bioactive compounds and antimicrobial activity of the oil fraction from the stem barks of Dacryodes edulis G. Lam. Int J Drug Dev Res 2009;1:117-25.

19. Sermakkani M, Thangapandian V. GCMS analysis of Cassia italica leaf methanol extract. Asian J Pharm Clin Res 2012;5:90-4 